\title{
Primary Headache Disorders in HIV-Infected Patients within a Hospital Setting in Sub-Saharan Africa, Benin Case: Prevalence and Associated Factors
}

\author{
Dieu Donne Gnonlonfoun ${ }^{*}$, Mendinatou Agbetou ${ }^{2}$, Armand Wanvoegbe ${ }^{3}$, \\ Constant Adjien1, Ronald Gnimavo ${ }^{1,4}$, Arlos Sowanou ${ }^{1}$, Rodrigue Domingo', \\ Joseph Adoco', Djimon Marcel Zannou ${ }^{3}$, Dismand Houinato ${ }^{1}$
}

${ }^{1}$ Department of Neurology, Teaching Hospital Center, Cotonou, Benin

${ }^{2}$ Department of Neurology, Teaching Hospital Center, Parakou, Benin

${ }^{3}$ Department of Internal Medicine, Teaching Hospital Center, Cotonou, Benin

${ }^{4}$ Department of Public Health, Ouidah, Benin

Email: *dieudonne.gnonlonfoun@gmail.com

How to cite this paper: Gnonlonfoun, D.D., Agbetou, M., Wanvoegbe, A., Adjien, C., Gnimavo, R., Sowanou, A., Domingo, R., Adoco, J., Zannou, D.M. and Houinato, D. (2019) Primary Headache Disorders in HIV-Infected Patients within a Hospital Setting in Sub-Saharan Africa, Benin Case: Prevalence and Associated Factors. World Journal of Neuroscience, 9, 282-293. https://doi.org/10.4236/wjns.2019.94021

Received: September 12, 2019 Accepted: November 18, 2019 Published: November 21, 2019

Copyright ( 2019 by author(s) and Scientific Research Publishing Inc. This work is licensed under the Creative Commons Attribution International License (CC BY 4.0).

http://creativecommons.org/licenses/by/4.0/

(c) (7) Open Access

\begin{abstract}
Introduction: Headache disorders are common in HIV-infected patients. These disorders are either primary or secondary. Objective: Determine prevalence and factors associated with primary headache disorders in HIV+ patients. Method: It was a cross-sectional, descriptive and analytical study conducted from $2^{\text {nd }}$ May 2017 to $2^{\text {nd }}$ August 2017 which included HIV+ patients aged 18 years and above. Diagnosis of primary headache disorders was carried out by a Neurologist on the basis of ICHD-II diagnostic criteria. The dependent variable was primary headache disorders. Epi Info Version 7.2.1.0 and STATA11 were used for data analysis. $\mathrm{P}<0.05$ was considered as significant value. Results: Primary headache disorders prevalence was $25.2 \%$ (124/493). Tension-type headache represented $77.41 \%$. HIV+ patients were aged $42.63 \pm$ 10.14 years. Sex-ratio was estimated at 0.14 . Factors associated with primary headache disorders in HIV+ patients were: male $(0.36$ [0.17 - 0.77]; $\mathrm{P}=$ 0.008), Dendi ethnicity (14.8 [2.08 - 101.99]; $\mathrm{P}=0.007)$, trader (3.09 [01.25 7.62]; $\mathrm{P}=0.02)$, WHO clinical stage (3.20 [1.43 - 7.17]; $\mathrm{P}=0.005)$, screening duration (1.01 [1.00 - 1.01]; $\mathrm{P}=0.00)$, hypertension (10.28 [4.44 - 23.83]; $\mathrm{P} \leq$ 0.001). Conclusion: This study helped to determine the standard profile of HIV+ patient with primary headache disorders. It will contribute to save costs associated with paraclinical examinations, while in search of secondary etiologies within an African context with limited financial resources.
\end{abstract}




\section{Keywords}

Primary Headache, HIV, Benin

\section{Introduction}

In the early 1980s, Acquired Immune Deficiency Syndrome (AIDS) pandemic was reported to the world without knowledge of the pathogen [1]. This form of this disease is the culmination of the progression of the immune system immunodeficiency virus (HIV). The pandemic is hitting sub-Saharan Africa, and according to UNAIDS data, $68 \%$ of the 33.2 million people living with HIV live in this region or less than $10 \%$ of the world's population. Headache disorders are common in HIV-infected patients [2] [3]. In Benin, these disorders in HIV+ population represent the second complaint among HIV-related neurological disorders with 5.2\% prevalence in Parakou in 2015 [4]. These headache disorders are either primary or secondary [4] [5] [6]. According to several authors, primary headache disorders are the most common. Kirkland reported respectively $86 \%$ and $14 \%$ prevalence for primary and secondary type of headache disorder [7]. Good knowledge of primary headache disorders in HIV+ patients could contribute to save costs associated with paraclinical examinations, while in search of secondary etiologies within an African context with limited financial resources. Hence, this study aims at determining prevalence and factors associated with primary headache disorders in HIV+ patients.

\section{Methods}

The study was conducted in the outpatient care referral Center for HIV+ patients in Cotonou. It was a cross-sectional, descriptive and analytical study conducted from $2^{\text {nd }}$ May to $2^{\text {nd }}$ August 2017. The study population comprised all HIV-infected patients seen during the study period. Comprehensive sampling was carried out. All patients meeting the inclusion criteria were included in the study, particularly patients aged 18 years and above with HIV+ serology. Sample size was 493 HIV+ patients.

Diagnosis criteria

Diagnosis of primary headache disorders (PHD) was carried out by a Neurologist on the basis of ICHD-II diagnostic criteria. Those excluded from the study were patients with secondary headache disorders according to ICHD-II criteria, especially red flags symptoms including: Sudden early headache disorder, deteriorating headache disorder, headache with fever, neck stiffness, rash, neurological signs, and acute pain during cough, physical effort, or Vasalva maneuver.

Variables

The dependent variable is "primary headache disorder" and independent variables included:

- Socio-demographic data: Age, gender, profession, marital status, ethnicity, 
socio-economic status.

- Medical history: Hypertension, diabetes, dyslipidemia.

- Seniority of HIV status.

- Patient's WHO clinical stage classified in stage I, II, III or IV.

- CD4 count: Latest CD4 count carried out during the study period.

- HIV serotype.

- Viral load: Patient latest viral load carried out during the study period.

Statistical analysis

Data collected were entered using Epi Info version 7.2.1.0 and analyzed with

Stata 11. First and foremost, we carried out description of the study variables, followed by bivariate analysis of independent variables. In fact, sample description was conducted with common statistics: standard quantitative variables were expressed through mean data \pm standard deviation. As regards quantitative variables which do not follow standard principles, median, minimum and maximum were determined. Qualitative variables were expressed through proportions. Proportions were compared with appropriate statistical tests including Pearson $\mathrm{chi}^{2}$, Student's $t$ or Fischer for comparison of mean values. Threshold value is estimated at $\mathrm{P}<0.05$. Thereafter, we conducted univariate analysis between "primary headache disorders" variable and the different characteristics of the study population. Finally, we developed the final model from multiple logistic regression analysis according to independent variables manual selection method. Variables included in the initial model are significantly associated with primary headache disorders onset in $\mathrm{HIV}+$ patients in univariate analysis with $\mathrm{P}$ $\leq 0.20$. In multivariate model, variables with threshold value estimated at $\mathrm{P}<$ 0.05 are considered as underlying factors for onset of primary headache disorders. For consistency of "goodness of fit" logistic model, we performed Hosmer-Lemshow test. Final, the P-value obtained (88.32\%) is greater than $5 \%$, so the final model is consistent. As a result, the model chosen is suitable to study factors associated with the onset of headache disorders in people living with HIV.

\section{Results}

Prevalence of primary headache disorders

Prevalence of primary headache disorders was $25.2 \%$ (124/493). The different types of primary headache disorders are highlighted in Table 1.

$\mathrm{HIV}+$ patients with primary headache disorders were aged $42.63 \pm 10.14$ years. Sex-ratio was estimated at 0.14 . Figure 1 highlights WHO clinical staging of HIV infection.

Clinical

Clinically, 79.03\% primary headache disorders commencement was related to HIV. The territory of headache disorders was much more frontal (93.54\%), and intensity was moderate (74.19\%). Other clinical characteristics of primary headache disorders in HIV+ patients are highlighted in Table 2.

Paraclinical and therapeutic

Biologically, all our HIV+ patients were infected with HIV-1 (100\%) including 
$23 \%$ with CD4 count $<200 \mathrm{cel} / \mu \mathrm{L}$. As regards therapy, $48 \%$ were under DUOVIR and (52\%) TENOLAM.

Factors associated with primary headache disorders in HIV+ patients

In univariate analysis

These factors are highlighted in Table 3.

In multivariate analysis

These factors are outlined in Table 4

The final model equation is obtained by taking the natural logarithm of odds ratio:

Logit $[\pi$ (Headache $=1 /$ Gender, Ethnicity, WHO clinical stage, Profession, Presence of hypertension, Screening duration) $]=-1.02$ (Male) +0.28 (Yoruba and related tribes) +2.68 (Dendis and related tribes) +1.18 (Mina and related tribes) -0.36 (Stage II) + 1.16 (Stage III) +0.66 (Stage IV) + 0.61 (Craftsman $)+$ 0.55 (Housewife) +1.13 (Trader) +1.39 (Student) -0.22 (Retired) +1.53 (Other) +2.33 (Presence of hypertension $)+0.009$ (Screening duration) -3.53 .

Figure 2 highlights the conceptual framework detailing factors associated with primary headache disorders in HIV+ patients.

As reflected in Figure 2, the standard profile of HIV+ patient with primary headache disorders in Cotonou is a female patient, hypertensive, trader, from Dendi or Mina ethnicity, with recent HIV screening, at WHO stage III.

In earlier stage of HIV infection, primary headache disorders risk development was high (7.31 at 3 months infection) and this risk decrease with the seniority of HIV infection (Figure 3 ).

\section{Discussion}

The cross-sectional, descriptive and analytical method used perfectly suits this type of study. Our study framework followed reason-based choice. In fact, the study was conducted in the outpatient care referral Center for HIV+ patients. This Center is highly patronized. Comprehensive sampling was conducted to avoid selection bias. Data collection was carried out through survey questionnaire. Diagnosis of primary headache disorders and the different types of primary headache disorders was executed by a neurologist on the basis of ICHD-II

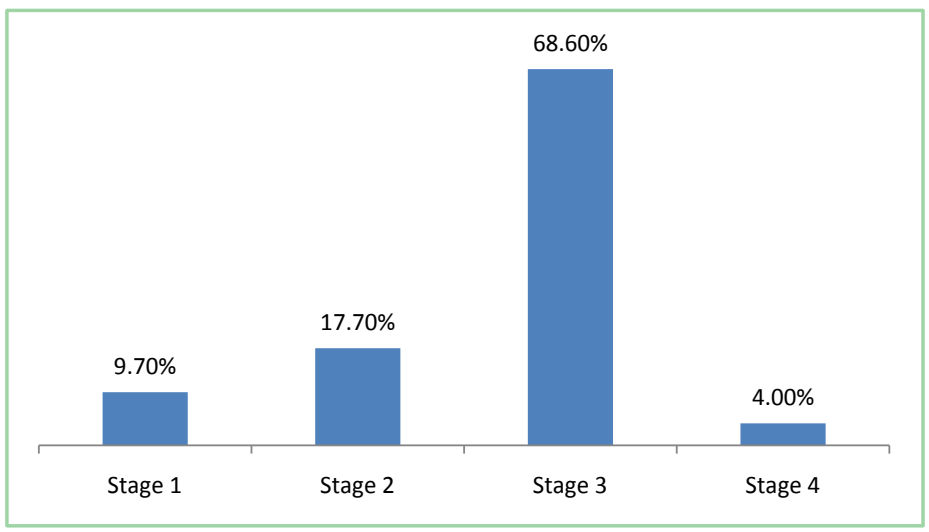

Figure 1. WHO clinical staging of HIV infection. 


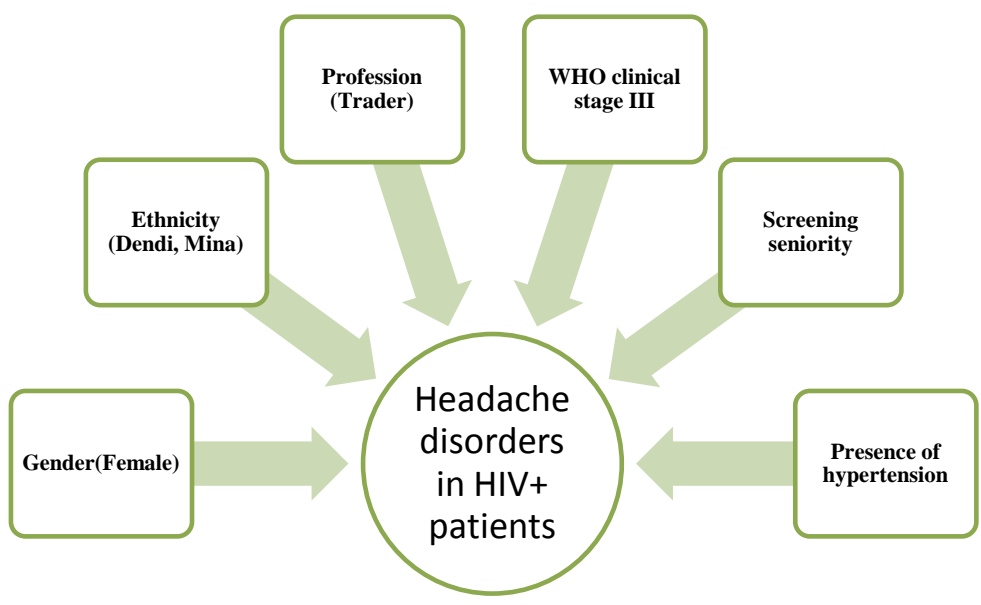

Figure 2. Framework detailing factors associated with onset of primary headache disorders in HIV+ patients.

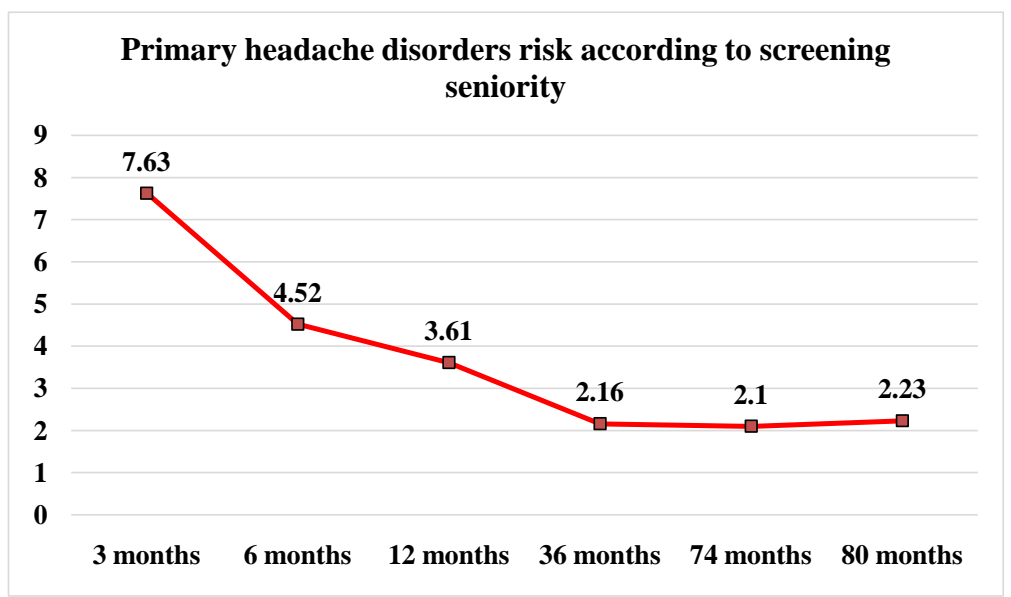

Figure 3. Primary headache disorders risk development according to HIV infection seniority.

Table 1. Distribution of category-based primary headache disorders in PLHIV, Cotonou 2017.

\begin{tabular}{ccc}
\hline & Total $(\mathrm{n}=124)$ & Percentage $(\%)$ \\
Rare ETH & 96 & 77.41 \\
Frequent ETH & 58 & 46.77 \\
Frequent TH & 35 & 28.22 \\
Migraine & 3 & 2.42 \\
Migraine without aura & 52 & 41.93 \\
Migraine with aura & 27 & 11.77 \\
Cluster headache & 24 & 19.50 \\
\end{tabular}

ETH: Episodic Tension-type Headache; TH: Tension-type Headache. 
Table 2. Distribution of headache disorders' characteristics in HIV+ patients, Cotonou 2017.

\begin{tabular}{|c|c|c|}
\hline & Total $(\mathrm{n}=124)$ & Percentage $(\%)$ \\
\hline \multicolumn{3}{|l|}{ Commencement related to HIV } \\
\hline Yes & 98 & 79.03 \\
\hline No & 26 & 20.96 \\
\hline \multicolumn{3}{|l|}{ At least 2 attacks } \\
\hline Yes & 124 & 100 \\
\hline No & 0 & 0 \\
\hline \multicolumn{3}{|l|}{ Duration of the attack untreated } \\
\hline Below $4 \mathrm{~h}$ & 43 & 34.67 \\
\hline $4 \mathrm{~h}-72 \mathrm{~h}$ & 81 & 65.32 \\
\hline \multicolumn{3}{|l|}{ Distribution of headache disorders } \\
\hline Unilateral & 28 & 22.58 \\
\hline Bilateral & 84 & 67.74 \\
\hline Side-switching & 12 & 9.67 \\
\hline \multicolumn{3}{|l|}{ Type of pain } \\
\hline Throbbing & 74 & 59.67 \\
\hline Aching & 66 & 53.22 \\
\hline Stabbing & 01 & 0.80 \\
\hline \multicolumn{3}{|l|}{ Territory } \\
\hline Frontal & 116 & 93.54 \\
\hline Occipital & 15 & 12.09 \\
\hline Maxillary & 1 & 0.80 \\
\hline Temporal & 26 & 20.96 \\
\hline Parietal & 34 & 27.41 \\
\hline Orbital & 2 & 1.61 \\
\hline \multicolumn{3}{|l|}{ Intensity } \\
\hline Low & 5 & 4.03 \\
\hline Moderate & 92 & 74.19 \\
\hline Severe & 27 & 21.77 \\
\hline \multicolumn{3}{|l|}{ Aggravating factor } \\
\hline Physical activities & 49 & 39.51 \\
\hline \multicolumn{3}{|l|}{ Associated signs } \\
\hline Nausea and vomiting & 16 & 12.90 \\
\hline Photophobia and phonophobia & 54 & 43.54 \\
\hline Visual disorders & 41 & 33.06 \\
\hline Sensory disorders & 14 & 11.29 \\
\hline Language disorders & 20 & 16.12 \\
\hline Vertigo & 55 & 44.35 \\
\hline
\end{tabular}


Table 3. Factors associated with primary headache disorders in HIV+ patients in univariate analysis.

\begin{tabular}{|c|c|c|c|}
\hline & Odds Ratio & $\mathrm{CI}_{95 \%}$ & P-value \\
\hline Age & & & 0.89 \\
\hline$>55$ years & 0.95 & $0.49-1.85$ & 0.89 \\
\hline$\leq 55$ years & 1 & - & - \\
\hline Gender & & & $\leq 0.001^{*}$ \\
\hline Male & 0.28 & $0.16-0.50$ & $\leq 0.001^{*}$ \\
\hline Female & 1 & - & - \\
\hline Ethnicity & & & 0.00 \\
\hline Fons and related tribes & 1 & - & - \\
\hline Yoruba and related tribes & 1.46 & $0.65-3.26$ & 0.356 \\
\hline Dendi and related tribes & 8.10 & $1.45-45.11$ & $0.017^{*}$ \\
\hline Mina and related tribes & 3.66 & $2.19-6.10$ & $\leq 0.001^{*}$ \\
\hline Marital status & & & 0.00 \\
\hline Single & 1 & - & - \\
\hline Married & 1.87 & $0.80-4.32$ & 0.145 \\
\hline Widow(er) & 5.52 & $2.19-13.91$ & $\leq 0.001^{*}$ \\
\hline Divorced & 5.01 & $1.99-12.56$ & $0.001^{*}$ \\
\hline \multicolumn{4}{|l|}{ Profession } \\
\hline Civil servant & 1 & - & - \\
\hline Craftsman & 2.50 & $1.05-5.93$ & $0.037^{*}$ \\
\hline Housewife & 3.43 & $1.43-8.20$ & $0.006^{*}$ \\
\hline Trader & 5.70 & $2.59-12.50$ & $\leq 0.001^{*}$ \\
\hline Student/Pupil & 3.37 & $0.75-15.05$ & 0.11 \\
\hline Retired & 5.06 & $0.41-62.16$ & 0.20 \\
\hline Hypertension & & & 0.00 \\
\hline Yes & 6.88 & $3.53-13.40$ & $\leq 0.001^{*}$ \\
\hline No & 1 & - & - \\
\hline Clinical stage & & & 0.00 \\
\hline Stage I & 1 & - & \\
\hline Stage II & 0.66 & $0.30-1.44$ & 0.29 \\
\hline Stage III & 2.43 & $1.23-4.81$ & $0.01^{*}$ \\
\hline Stage IV & 1.10 & $0.34-3.53$ & 0.87 \\
\hline CD4 count & 0.87 & $0.54-1.41$ & 0.59 \\
\hline Duovir-based therapy & 0.33 & $0.30-1.21$ & 0.32 \\
\hline Screening duration & 1.00 & $1.00-1.01$ & $\leq 0.001^{*}$ \\
\hline
\end{tabular}

*Significant result. 
Table 4. Factors associated with primary headache disorders in multivariate analysis.

\begin{tabular}{|c|c|c|c|}
\hline & Odds Ratio & $\mathrm{CI}_{95 \%}$ & $\mathrm{P}$-value \\
\hline Gender & 0.36 & $0.17-0.77$ & $0.008^{*}$ \\
\hline \multicolumn{4}{|l|}{ Ethnicity } \\
\hline Fon and related tribes & 1 & & \\
\hline Yoruba and related tribes & 1.33 & $0.53-3.37$ & 0.55 \\
\hline Dendi and related tribes & 14.58 & $2.08-101.99$ & $0.007^{*}$ \\
\hline Mina and related tribes & 3.24 & $1.75-6.01$ & $\leq 0.001^{*}$ \\
\hline \multicolumn{4}{|l|}{ Profession } \\
\hline Civil servant & 1 & & \\
\hline Craftsman & 1.85 & $0.71-4.80$ & 0.20 \\
\hline Housewife & 1.73 & $0.63-4.75$ & 0.29 \\
\hline Trader & 3.09 & $1.25-7.62$ & $0.02^{*}$ \\
\hline Student/Pupil & 4.02 & $0.76-21.17$ & 0.10 \\
\hline Retired & 0.80 & $0.05-13.20$ & 0.88 \\
\hline Other & 4.63 & $0.36-59.27$ & 0.24 \\
\hline \multicolumn{4}{|l|}{ Clinical stage } \\
\hline Stage I & 1 & & \\
\hline Stage II & 0.70 & $0.28-1.72$ & 0.43 \\
\hline Stage III & 3.20 & $1.43-7.17$ & $0.005^{*}$ \\
\hline Stage IV & 1.94 & $0.52-7.18$ & 0.32 \\
\hline Screening duration & 1.01 & $1.00-1.01$ & $\leq 0.001^{*}$ \\
\hline Hypertension & 10.28 & $4.44-23.83$ & $\leq 0.001^{*}$ \\
\hline
\end{tabular}

*Significant result.

criteria, which provides high accuracy for our study. The analysis method, especially in identification of associated factors, enabled to reduce all confounding factors and singled out factors really independently associated with primary headache disorders in HIV+ patients. Nevertheless, this study is limited, having been conducted in a single center on the basis of non-probabilistic sampling. Another limitation of the study is absence of medical imaging, in particular brain scanner and MRI to confirm absence of brain injury and by extension absence of secondary headache disorders in our patients.

In our study, prevalence of primary headache disorders is $25.2 \%$. This rate is similar to $25 \%$ reported by Mirsattari et al. in 1996 [5] and 22\% recorded by Hewett et al. in 1997 [8]. This could be the result of similar methodology used by these authors. In fact, these studies were all cross-sectional with comprehensive census of patients seen for routine consultation during the whole study period, in view of monitoring HIV. Furthermore, they were virtually conducted during the same period, within less than one year interval. This prevalence found in our 
series is significantly higher than 5.2\% reported by Adoukonou et al. in Parakou in 2014 [9]. This gap in prevalence could be explained by the fact that the study method was dissimilar, and the study populations have different socio-cultural backgrounds; in other words pain tolerance is different for the two populations.

Primary headache disorders were primarily represented by tension-type headache $(77.41 \%)$, followed by migraine $(41.93 \%)$. Similar results were found in Evers et al. [10] and Holloway et al. [6] series. Indeed, Evers et al. reported prevalence of tension-type headache representing $45.8 \%$ of primary headache disorders in his series, whereas migraines represented $16 \%$ and other types of primary headache disorders only $6.1 \%$. Holloway et al. recorded the same findings at the end of their study. These different studies reveal clear prevalence of tension-type headache in HIV+ patients. The first reason is that tension-type headache is the most common type of primary headache disorders in general population [11]. More so, as these headache disorders are most often of psychogenic origin, one could interpret that the anxiety triggered by this serological status in patients can primarily cause this type of headache. Finally most of these headache disorders were reported by patients receiving ARV, and considering the fact that antiretroviral therapy inhibits release of several neurotransmitters such as glutamate, tryptophan and substance $\mathrm{P}$ which are all involved in migraine pathophysiology; this could then justify the low rate of migraine headache [12].

Several factors were identified as associated with onset of primary headache disorders in HIV+ patients. In fact, gender is significantly associated with onset of primary headache disorders in $\mathrm{HIV}+$ patients included in our study with $\mathrm{P}$-value estimated at 0.008 . OR value was 0.36 ; this clearly shows that being a male constitutes a protective factor against onset of headache disorders in HIV+ patients, adjusted on the other explanatory variables. In other words, the risk of onset of headache disorders is higher in HIV+ women than men, taking into account the other explanatory variables. This corroborates the result reported by Hewitt et al. [8]. This result can be explained by the fact that females were more vulnerable to the virus [13]. In our study, HIV+ traders/vendors are 3 times more vulnerable to risk of headache disorders than civil servants. This result may be due to the fact that these patients generally have no steady source of livelihood and are therefore continuously concerned about daily earning. This triggers stress, thereby sustaining headache disorders in this segment of the population. Unconducive working conditions (sun, rain, heat, noise ...) are also fertile ground to onset of headache disorders in these patients.

WHO clinical stage III of HIV is significantly associated with onset of primary headache disorders in PLHIV with P-value estimated at 0.005. Thus, HIV+ patients at WHO clinical stage III are more at risk to develop headache disorders that those who are not. This risk is estimated at 3 for those who are at stage III in comparison with stage I patients. Evers et al. [10] reported a similar result. This may be explained by the fact that WHO advanced clinical stage reflects deep immunosuppression, and the more advanced immunosuppression, the more headache disorders onset [6] [12]. 
Duration of HIV screening is also significantly associated with primary headache disorders in HIV+ patients, with P-value $<0.0001$. More recent the screening is, higher is the risk. In that regard, HIV+ patients screened three (03) months and eighty (80) months ago are respectively 7 and 2 times more vulnerable risk of primary headache. Disclosure of HIV seropositivity triggering important psychological stress the first months [14] and the ensuing stigma are all psychological factors which could explain onset of primary headache disorders in HIV+ patients. Patients diagnosed with HIV receive ARV therapy, and therefore develop less primary headache disorders compared with the general population [15]. In fact, ARV therapy prevents viral growth and reduces the circulating level of neurotransmitters involved in onset of migraine [16]. As a result, less cases of migraine are recorded and the proportion of primary headache disorders drops in HIV+ patients receiving ARV therapy.

In our study population, frequency of hypertension was $8.72 \%$ and HIV+ hypertensive patients were 10.28 times more exposed to the risk of primary headache disorders. In fact, hypertension is one of the leading factors exacerbating the frequency and severity of headache disorders. According to Stewart et al. [17], it also constitutes a cardiovascular risk factor of which, diagnosis and disclosure to patients already trigger psychological stress, and therefore headache disorders. Scher et al. [18] in the Netherlands and Entonen et al. in Finland [19] made the same observations in their studies.

\section{Conclusion}

In the African context with limited technical and financial accessibility, identification of the standard profile of HIV+ patient with primary headache disorders provides medical practitioners with a tool which will contribute to save costs associated with paraclinical examinations, in search of secondary etiologies.

\section{Conflicts of Interest}

The authors declare no conflicts of interest regarding the publication of this paper.

\section{References}

[1] Poiesz, B.J., Ruscetti, F.W., Gazdar, A.F., Bunn, P.A., Minna, J.D. and Gallo, R.C. (1980) Detection and Isolation of Type C Retrovirus Particles from Fresh and Cultured Lymphocytes of a Patient with Cutaneous T-Cell Lymphoma. Proceedings of the National Academy of Sciences of the United States of America, 77, 7415-7419. https://doi.org/10.1073/pnas.77.12.7415

[2] Creamer, A., Ioannidis, S., Wilhelm, T., Mahangu, T. and Lipman, M. (2016) Headache in an HIV Positive Patient: Diagnostic Challenges and Approach to Treatment. Journal of Clinical Medicine, 16, 548-550. https://doi.org/10.7861/clinmedicine.16-6-548

[3] Graham, C.B., Wippold, F.J., Pilgram, T.K., Fisher, E.J. and Smoker, W.R. (2000) Screening CT of the Brain Determined by CD4 Count in HIV-Positive Patients Presenting with Headache. American Journal of Neuroradiology, 21, 451-454. 
[4] Adoukonou, T., Dassi-Gbenou, J., Glele, R.A., Dovonou, A., Kpangon, A. and Houinato, D. (2015) Épidémiologie des affections neurologiques dans une population de personnes vivant avec le VIH à Parakou en 2014. Revista de Neurología (Paris), 171, A136. https://doi.org/10.1016/j.neurol.2015.01.295

[5] Mirsattari, S.M., Power, C. and Nath, A. (1999) Primary Headaches in HIV-Infected Patients. Headache, 39, 3-10. https://doi.org/10.1046/j.1526-4610.1999.3901003.x

[6] Holloway, R.G. and Kieburtz, K.D. (1995) Headache and the Human Immunodeficiency Virus Type I Infection. Headache: The Journal of Head and Face Pain, 35, 245-255. https://doi.org/10.1111/j.1526-4610.1995.hed3505245.x

[7] Kirkland, K.E., Kirkland, K., Smitherman, T.A., et al. (2012) Headache among Patients with HIV Disease: Prevalence, Characteristics, and Associations. Headache: The Journal of Head and Face Pain, 52, 455-466.

https://doi.org/10.1111/j.1526-4610.2011.02025.x

[8] Hewitt, D.J., McDonald, M., Portenoy, R.K., Rosenfeld, B., Passik, S. and Breitbart, W. (1997) Pain Syndromes and Etiologies in Ambulatory AIDS Patients. Pain, 70, 117-123. https://doi.org/10.1016/S0304-3959(96)03281-2

[9] Berger, J.R., Stein, N. and Pall, L. (1996) Headache and Human Immunodeficiency Virus Infection: A Case Control Study. European Neurology, 36, 229-233. https://doi.org/10.1159/000117255

[10] Evers, S., Wibbeke, B., Reichelt, D., Suhr, B., Brilla, R. and Husstedt, I. (2000) The Impact of HIV Infection on Primary Headache. Unexpected Findings from Retrospective, Cross-Sectional, and Prospective Analyses. Pain, 85, 191-200. https://doi.org/10.1016/S0304-3959(99)00266-3

[11] Jay, G.W. and Barkin, R.L. (2017) Primary Headache Disorders Part 2: Tension-Type Headache and Medication Overuse Headache. Disease-A-Month, 63, 342-367. https://doi.org/10.1016/j.disamonth.2017.05.001

[12] Joshi, S.G. and Cho, T.A. (2014) Pathophysiological Mechanisms of Headache in Patients with HIV. Headache, 54, 946-950. https://doi.org/10.1111/head.12356

[13] Siedner, M.J., et al. (2014) Treatment as Long-Term Prevention: Sustained Reduction in HIV Sexual Transmission Risk with Use of Antiretroviral Therapy in Rural Uganda. AIDS, 28, 267-271. https://doi.org/10.1097/QAD.0000000000000136

[14] Genis, P., et al. (1992) Cytokines and Arachidonic Metabolites Produced during Human Immunodeficiency Virus (HIV)-Infected Macrophage-Astroglia Interactions: Implications for the Neuropathogenesis of HIV Disease. The Journal of Experimental Medicine, 176, 1703-1718. https://doi.org/10.1084/jem.176.6.1703

[15] Sanya, E.O., Desalu, O.O., Aderibigbe, S.A., Kolo, P.M., Mustapha, A.F. and Adeyanju, O.A. (2017) Prevalence and Clinical Characteristics of Headaches among Undergraduate Students in Three Tertiary Institutions in Ilorin, Nigeria. Nigerian Journal of Clinical Practice, 20, 1411-1416. https://doi.org/10.4103/njcp.njcp_383_16

[16] Almalki, Z.A., et al. (2018) Prevalence of Migraine Headache in Taif City, Saudi Arabia. Journal of Clinical Medicine Research, 10, 125-133. https://doi.org/10.14740/jocmr3277w

[17] Bigal, M.E., et al. (2010) Migraine and Cardiovascular Disease: A Population-Based Study. Neurology, 74, 628-635. https://doi.org/10.1212/WNL.0b013e3181d0cc8b

[18] Scher, A.I., Terwindt, G.M., Picavet, H.S.J., Verschuren, W.M.M., Ferrari, M.D. and Launer, L.J. (2005) Cardiovascular Risk Factors and Migraine: The GEM Population-Based Study. Neurology, 64, 614-620. 
https://doi.org/10.1212/01.WNL.0000151857.43225.49

[19] Entonen, A.H., et al. (2014) Migraine Predicts Hypertension-A Cohort Study of the Finnish Working-Age Population. European Journal of Public Health, 24, 244-248. https://doi.org/10.1093/eurpub/ckt141 